\title{
What is chemistry that I may teach it?
}

\author{
Peter G. Nelson ${ }^{1}$
}

Published online: 7 May 2018

(C) The Author(s) 2018

\begin{abstract}
This article presents a personal answer to the question "What is chemistry?", set out in terms of six propositions. These cover "pure" and "applied" chemistry, different levels of description, and the broader context of chemistry.
\end{abstract}

Keywords "Pure" . "Applied" · Bulk · Macroscopic · Atomic · Electronic · Chemical instinct · Periodic Table · Acid · Base · Rational · Intuitive · Cerebral · Practical ·

Analytical

The question "What is chemistry?" is not one that we, as chemists, are inclined to give much attention to. We tend to assume that we all know what chemistry is. Thus it is that, in his book, "The Concept of Law", Professor H.L.A. Hart is able to write (1961: p. 1):

No vast literature is dedicated to answering the questions "What is chemistry" or "What is medicine?", as it is to the question "What is law?" A few lines in an elementary textbook is all the student of these sciences is asked to consider.

My conviction is, however, that the answer to the question "What is chemistry?" is not as obvious as we may think, and that behind different views about the teaching of chemistry lie different conceptions as to what chemistry is.

In this article, my aim is to open up the question, and to stimulate discussion of it. I do this by presenting a personal answer to it, set out in terms of six propositions. I also draw out the implications of each proposition for teaching the subject.

Peter G. Nelson

p.g.nelson@hull.ac.uk

1 Department of Chemistry, University of Hull, Hull HU6 7RX, UK 


\section{"Pure" and "applied"}

My first proposition is that chemistry embraces two quite distinct activities, with only a partial connection between them. These are (1) the quest for an understanding of substances and their interconversion, and (2) the making of materials and utilization of their properties for human ends. These two activities are usually called "pure" chemistry and "applied" chemistry, but I would suggest that the relationship between them is not as close as this- "applied" chemistry is not simply the application of the understanding of substances gained through "pure" chemistry. 1

In support of this, I would cite the following:

(1) "Applied" chemistry existed long before any progress was made in "pure" chemistry, the foundations of which were only laid in the latter part of the 18th century. For several thousand years before this, a wide variety of chemical techniques had been in use, some of which required considerable technical skill (Sherwood Taylor 1957). Examples are the extraction of metals, the production of glaze and glass, the dyeing of cloth, and the making of soap. This picture continued even into the early stages of the Industrial Revolution from about 1760 onwards, when the increased demand for materials by the textiles industry was met by scaling up existing processes. It was only as the science of chemistry became established later in the same century (Lavoisier's "Traité Élémentaire de Chimie" was published in 1789) that "pure" chemistry began to have a significant influence on "applied" chemistry.

(2) The impact of "pure" chemistry on "applied" chemistry since the late 18th century, though very considerable indeed, has nevertheless only been partial. Thus:

(i) Some chemical processes that were in use before the late 18th century are still in use today, albeit in much improved form. Obvious examples are the manufacture of iron and steel and the production of glass.

(ii) Although many of the innovations in "applied" chemistry have been a direct result of discoveries in "pure" chemistry, many others have come from research and development of a more empirical character, there having been relatively little understanding of the processes taking place (cf. Langrish et al. 1972). A good example is provided by the first synthetic rubbers and plastics. These were devised before the essential constitution of such materials was known, and it was only later that they were found to be high polymers.

(iii) Considerable use is made of empirical procedures in much of the current research and development in "applied" chemistry. This is so, for example, in the area of heterogeneous catalysis of organic reactions. The reason for this is clear enough. "Pure" chemistry is still a long way off its goal of achieving a detailed understanding of matter, especially of the relatively complicated systems "applied" chemists often have to deal with, so that the help that it can give to those working on "applied" problems is in many cases limited.

(3) Even if "pure" chemistry were capable of answering all the questions "applied" chemists would like it to answer, "applied" chemistry would still be more than simply "pure"

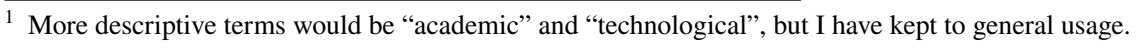


chemistry put into practice. The point is that the way in which a particular job is done in "applied" chemistry is not determined by chemical considerations only, but by a complex mixture of these and a whole host of other considerations-availability of materials, engineering, economics, safety, etc. "Applied" chemistry is thus more than an applied science, in the same way that engineering is more than applied mechanics and medicine is more than applied physiology.

(4) The attention that different areas of "pure" chemistry have received, though in some cases very much determined by their importance, or potential importance, to "applied" chemistry, has in other cases been relatively little determined by this consideration. This is partly inevitable - the quest for an understanding of matter is bound to take the "pure" chemist into areas where the chances of making useful discoveries are small. It is also a matter of ideology. While some "pure" chemists believe that one of the aims of trying to obtain an understanding of matter is to assist in its utilization, and are committed to doing work that is either of immediate value to "applied" chemistry, or of such a fundamental or novel character that there is a definite chance that "applied" chemistry might eventually benefit from it, other "pure" chemists do not have as strong a commitment towards helping "applied" chemistry, and choose topics to work on that are less likely to lead to practical applications. The net result is that the development of "pure" chemistry has only partly reflected the needs and aims of "applied" chemistry, notwithstanding the very useful discoveries that have sometimes been made in areas of the subject that would not have been expected to produce them.

My first thesis is, then, that chemistry embraces two distinct activities, neither of which can be said to subsume the other. This means that we should not think of "applied" chemistry as being inferior to "pure" chemistry, as does the author of one school textbook, who says that, of the two sides of chemistry, "pure" chemistry is "infinitely the more important" (quoted by Hughes 1975, p. 111). Nor should we think of chemistry simply as a science as does the "Oxford English Dictionary". The more empirical aspects of "applied" chemistry are as much art as science. No, we should hold the two sides of chemistry together, and think of it in terms of both "pure" and "applied". 2

\section{Implications for teaching}

If my thesis is right, teachers need to give the same kind of attention to the "applied" side as they give to the "pure". The common practice of systematically developing the "pure" side, and tagging on applications at the end, as if the know-how for the latter came exclusively from the former, misrepresents the "applied" side as we have seen. The latter needs to be developed in its own right, and students need to be taught to think, not just in "pure" terms (e.g. of whether a substance is "ionic", "covalent, or "metallic"), but also in applied (e.g. of whether a substance is cheap or expensive). They also need to learn the names

\footnotetext{
2 The word "chemistry" has ranged in meaning over both sides of the subject in the past (see, e.g., Partington 1957). In the third century A.D., it referred to the fraudulent practise of imitating precious metals and stones (Greek khèmia). By the Middle Ages, this practice had evolved into the quest for a substance that would actually transmute base metals into gold (Arabic alkīmīa, adding the article $a l$ ). In the 16th century, following the redirection of alchemy by Paracelsus, the word (without the article) came to mean the making of medicines, hence the popular meaning of "chemist" today. Finally, in the seventeenth and eighteenth centuries, following Boyle's critique of alchemical theory in "The Sceptical Chymist" of 1661, the word came to mean the study of matter scientifically, as in today's OED definition.
} 
"applied" chemists use for substances where these differ from the ones "pure" chemists use (e.g. "acetylene" not "ethyne", "lime" not "calcium oxide").

One way of helping students to acquire a balanced view of chemistry is by presenting some "applied" chemistry to them before any "pure" chemistry. This can be done by describing how materials like brick, lime, glass, steel, and soap are made without going into "pure" chemical details. The resulting descriptive chemistry can then be used as a basis for developing chemical theory. This approach was suggested by a reviewer, and is one I take in my e-book, "Introduction to Chemistry" (Nelson 2017). It also helps to solve some of the other problems I identify in this article.

\section{Levels of description}

My second proposition is that chemists think about materials at three levels (Nelson 2002):

(1) the bulk level (the level of solids, liquids, and gases),

(2) the atomic level (the level of atoms, ions, radicals, and molecules),

(3) the electronic level (the level of electrons and nuclei).

The task of making chemical ideas meaningful, therefore, is not simply a question of making them meaningful at the level at which each one is set, but of relating them meaningfully to the other two levels. Otherwise, students' understanding at one level will be completely divorced from that at another.

An illustration will make this clear. Suppose that we were to introduce chemistry entirely at the atomic and electronic level. In due course, our students would be able to work out the electronic configurations of different atoms, and the ways in which atoms that do not have a closed-shell configuration can combine with other such atoms to achieve this configuration. They would then be able to say, for example, that atoms with an atomic number of one (for which they have learnt to use the symbol $\mathrm{H}$ ) join together in pairs to form $\mathrm{H}_{2}$ molecules, that atoms with a nuclear charge of 17 (symbol $\mathrm{Cl}$ ) join together similarly to form $\mathrm{Cl}_{2}$ molecules, and that $\mathrm{H}_{2}$ molecules and $\mathrm{Cl}_{2}$ molecules interact with each other to form $\mathrm{HCl}$ molecules. To them, however, this statement would bear no relation at all to there being a light, colourless, inflammable gas that we call hydrogen and a choking, yellowish-green gas that we call chlorine, which will burn in each other to form a colourless, fuming, acidic gas, hydrogen chloride. As far as they would be concerned, the symbols $\mathrm{H}$ and $\mathrm{Cl}$, and the names "hydrogen" and "chlorine" would just be cyphers. Thus, though very proficient at two levels, they would be completely ignorant with respect to the third.

This is, I know, an extreme example. It is, however, all too easy to produce students whose grasp of chemistry at the macroscopic level is weak. Davenport (1970) famously told of a student who thought that silver chloride was a pale green gas, and could offer a reason why. Others have reported similar misconceptions since. I do not have to say that such ignorance is bad. If my doctor's grasp of medicine was as weak as this, I would be very worried indeed.

The best way of solving this problem is to introduce chemistry progressively, starting at the bulk level and gradually working down to the electronic (Nelson 2002, 2017). This enables links to be made between the levels at each stage in the presentation. 


\section{"Pure" chemistry: its character}

My third proposition is that our present understanding of substances varies in character from one area of the subject to another, from being, at one extreme, more or less completely "rational", to being, at the other, more or less completely "intuitive". By a "rational" understanding, I mean one that is rigorously expressible in the form of a set of principles, from which the behaviour of different systems can be derived by deduction; by an "intuitive" understanding, I mean one that is incapable of being expressed in a completely rigorous way, but which nevertheless allows us to make predictions with a fair degree of accuracy.

An example of the first kind of understanding is that provided by thermodynamics. In the form in which we now have it, this consists of a relatively small number of basic principles (principally the first, second, and third laws), from which a wide variety of relations can be derived mathematically. From such relations, an accurate value for one property can be obtained from accurate values of other properties. A practical example is the calculation of the equilibrium pressures for the conversion of graphite into diamond at different temperatures from the heat of combustion, heat capacities, and equation of state for each form (Berman and Simon 1955; Bundy et al. 1955).

An example of the second kind of understanding is that possessed by preparative organic chemists when confronted with a reaction that is not proceeding in the way they want it to, and they "hit on" what to do to get it to work (e.g. they may add a little acid to it). Sometimes when they do this, they may be able to explain very easily why they chose the modification they did ("I have found before that a little acid helps this kind of reaction to go" or "I remember reading somewhere that acids catalyse reactions of this type" or "I worked it out from the likely mechanism of the reaction"), but this is not always the case, and in the limit they may find an explanation almost impossible. They are then in some way drawing on their experience of organic reactions without going through the conscious process of formulating principles and making deductions from them.

Lewis (1926, pp. 174-175) called this kind of understanding "chemical instinct":

... as the organic chemist acquires proficiency in [the] art [of making new substances], for indeed it is almost an art, he acquires an intimate acquaintance with his material. This leads him to a few great generalizations, to a large number of working rules of limited or sporadic applicability, and to many vague guesses or little tricks of thought, which he cannot or will not impart to others. In fact, much of his knowledge does not fully emerge into his own scientific consciousness, and has been called chemical instinct (chemisches Gefühl); yet it is extraordinary with what precision he will calculate the properties of a substance he has never seen or the consequences of a reaction he has never tried.

Today's organic chemists have more help from theory than in Lewis's time, but still need chemical instinct.

A good deal of our present understanding of materials lies between the two extremes I have just described. Take, for example, the Periodic Table. In the words of Mendeleev (1891, p. 16, note 6), the basis of this is that: 
Table 1 Highest classical valencies of the elements. Reproduced with permission from Nelson (2013), Wang et al. (2014) and Johnson and Nelson (2018)

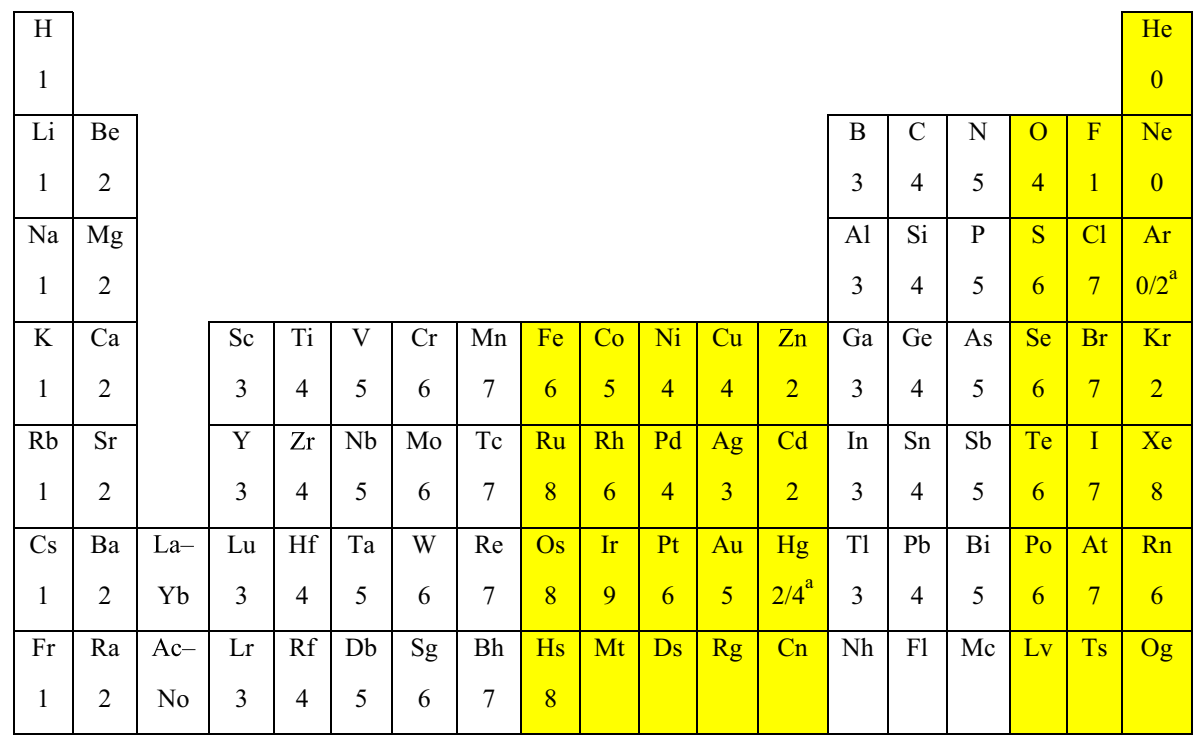

\begin{tabular}{|c|c|c|c|c|c|c|c|c|c|c|c|c|c|}
\hline $\mathrm{La}$ & $\mathrm{Ce}$ & $\mathrm{Pr}$ & $\mathrm{Nd}$ & $\mathrm{Pm}$ & $\mathrm{Sm}$ & $\mathrm{Eu}$ & $\mathrm{Gd}$ & $\mathrm{Tb}$ & $\mathrm{Dy}$ & $\mathrm{Ho}$ & $\mathrm{Er}$ & $\mathrm{Tm}$ & $\mathrm{Yb}$ \\
3 & 4 & 5 & 4 & 3 & 3 & 3 & 3 & 4 & 4 & 3 & 3 & 3 & 3 \\
\hline $\mathrm{Ac}$ & $\mathrm{Th}$ & $\mathrm{Pa}$ & $\mathrm{U}$ & $\mathrm{Np}$ & $\mathrm{Pu}$ & $\mathrm{Am}$ & $\mathrm{Cm}$ & $\mathrm{Bk}$ & $\mathrm{Cf}$ & $\mathrm{Es}$ & $\mathrm{Fm}$ & $\mathrm{Md}$ & $\mathrm{No}$ \\
3 & 4 & 5 & 6 & 7 & 7 & 6 & 4 & 4 & 4 & 3 & 3 & 3 & 3 \\
\hline
\end{tabular}

Highlighted: groups in which the highest valencies differ

${ }^{\mathrm{a}}$ In matrix-isolated species

(1) The elements, if arranged according to their atomic weights, exhibit an evident periodicity of properties.

(2) Elements which are similar as regards their chemical properties have atomic weights which are either of nearly the same value (platinum, iridium, osmium) or which increase regularly (e.g. potassium, rubidium, caesium).

(3) The arrangement of the elements or of groups of elements in the order of their atomic weights, corresponds with their so-called valencies.

Unlike the laws of thermodynamics, however, these principles only hold true very loosely. Thus, contrary to principle (2), there are some elements with similar properties whose atomic weights are not related in a simple way. Partington (1946, p. 182) has written: "It must be admitted ... that some older classifications bring some very similar elements together which are separated in the Periodic Table." Indeed, in order to produce his periodic system, Mendeleev had to alter the atomic weights of some of the elements for which values had been assigned on the basis of chemical similarities (e.g. the atomic weight of beryllium had been fixed at three times its equivalent weight on the basis of its similarity to aluminium).

Again, principle (3), even when restricted to the highest valencies of the elements, and atomic weight is replaced by atomic number, is only an approximation. It holds 
Table 2 Outer electronic configurations of atoms of the elements in their ground states. Reproduced with permission from Nelson (2013)

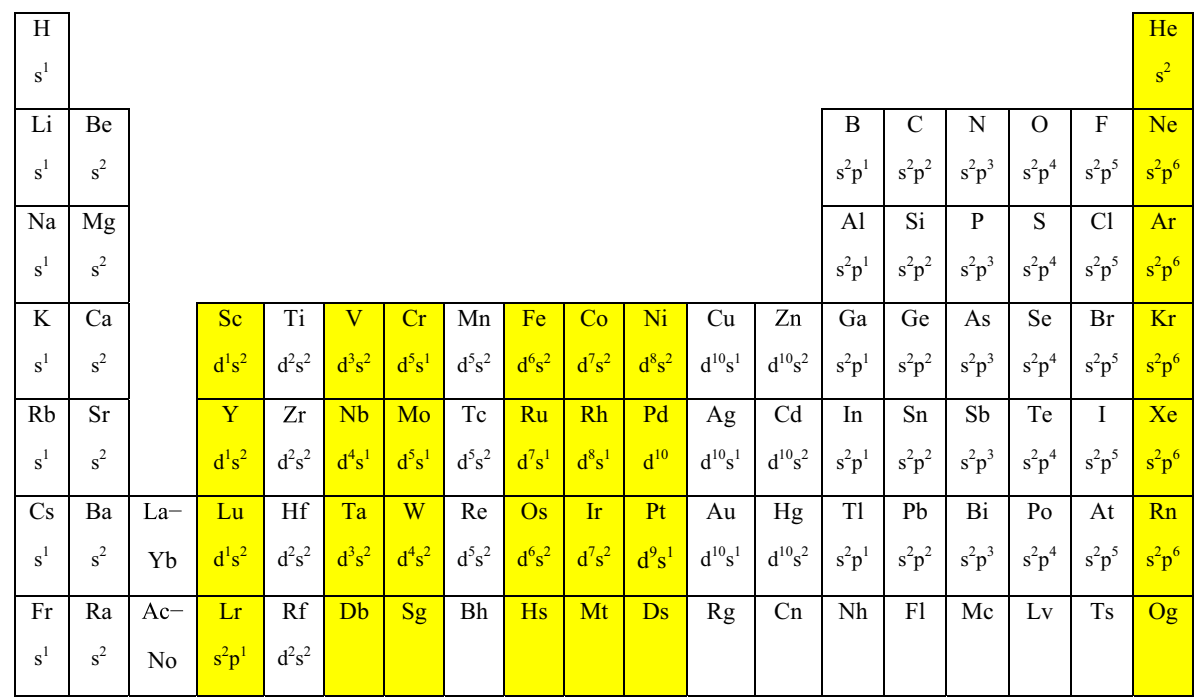

\begin{tabular}{|c|c|c|c|c|c|c|c|c|c|c|c|c|c|}
\hline $\begin{array}{l}\mathrm{La} \\
\mathrm{d}^{1} \mathrm{~s}^{2}\end{array}$ & $\begin{array}{c}\mathrm{Ce} \\
\mathrm{f}^{1} \mathrm{~d}^{1} \mathrm{~s}^{2}\end{array}$ & $\begin{array}{c}\operatorname{Pr} \\
\mathrm{f}^{3} \mathrm{~s}^{2}\end{array}$ & $\begin{array}{l}\mathrm{Nd} \\
\mathrm{f}^{4} \mathrm{~s}^{2}\end{array}$ & $\begin{array}{l}\mathrm{Pm} \\
\mathrm{f}^{5} \mathrm{~s}^{2}\end{array}$ & $\begin{array}{l}\mathrm{Sm} \\
\mathrm{f}^{6} \mathrm{~s}^{2}\end{array}$ & $\begin{array}{l}\mathrm{Eu} \\
\mathrm{f}^{7} \mathrm{~s}^{2}\end{array}$ & $\begin{array}{l}\mathrm{Gd} \\
\mathrm{f}^{7} \mathrm{~d}^{1} \mathrm{~s}^{2}\end{array}$ & $\begin{array}{l}\mathrm{Tb} \\
\mathrm{f}^{9} \mathrm{~s}^{2}\end{array}$ & $\begin{array}{l}\text { Dy } \\
\mathrm{f}^{10} \mathrm{~s}^{2}\end{array}$ & $\begin{array}{l}\text { Ho } \\
\mathrm{f}^{11} \mathrm{~s}^{2}\end{array}$ & $\begin{array}{c}\mathrm{Er} \\
\mathrm{f}^{12} \mathrm{~s}^{2}\end{array}$ & $\begin{array}{l}\mathrm{Tm} \\
\mathrm{f}^{13} \mathrm{~s}^{2}\end{array}$ & $\begin{array}{l}\mathrm{Yb} \\
\mathrm{f}^{14} \mathrm{~s}^{2}\end{array}$ \\
\hline Ac & Th & $\mathrm{Pa}$ & $\mathrm{U}$ & $\mathrm{Np}$ & $\mathrm{Pu}$ & $\mathrm{Am}$ & $\mathrm{Cm}$ & $\mathrm{Bk}$ & $\mathrm{Cf}$ & Es & $\mathrm{Fm}$ & $\mathrm{Md}$ & No \\
\hline $\mathrm{d}^{1} \mathrm{~s}^{2}$ & $d^{2} s^{2}$ & $f^{2} d^{1} s^{2}$ & $\mathrm{f}^{3} \mathrm{~d}^{1} \mathrm{~s}^{2}$ & $f^{4} d^{1} s^{2}$ & $f^{6} s^{2}$ & $\mathrm{f}^{7} \mathrm{~s}^{2}$ & $\mathrm{f}^{7} \mathrm{~d}^{1} \mathrm{~s}^{2}$ & $f^{9} s^{2}$ & $\mathrm{f}^{10} \mathrm{~s}^{2}$ & $\mathrm{f}^{11} \mathrm{~s}^{2}$ & $\mathrm{f}^{12} \mathrm{~s}^{2}$ & $f^{13} s^{2}$ & $\mathrm{f}^{14} \mathrm{~s}^{2}$ \\
\hline
\end{tabular}

Highlighted: groups in which configurations differ

beautifully for some groups, but fails for others (see Table 1). Moreover, even if we go beyond Mendeleev, and base the Periodic Table on electronic configuration, it still remains imprecise. Elements in in the same vertical group do not always have the same outer electronic configuration (see Table 2), and elements with the same configuration are not always related chemically (helium, $1 s^{2}$; beryllium, $2 s^{2}$ ). All this means that the application of the periodic law is not simply a question of making logical deductions from basic principles as it is in the case of thermodynamics. It involves rather a fairly thorough knowledge of how the principles work out in practice-of exceptions, trends, and patterns - so that a particular logical deduction can be appraised and if necessary adjusted. In the limit, the process becomes virtually intuitive.

Thus while Mendeleev was able to predict the existence and the chemistry of the missing elements eka-boron, eka-aluminium, and eka-silicon (scandium, gallium, and germanium) with considerable certainty, he was much more tentative when it came to other elements. In his Faraday Lecture of 1889 he said (Mendeleev 1889):

I foresee some more new elements, but not with the same certitude as before. I shall give one example, and yet I do not see it quite distinctly. In the series which contains $\mathrm{Hg}=204, \mathrm{~Pb}=206$, and $\mathrm{Bi}=208$, we can guess the existence $\ldots$ of an element analogous to tellurium, which we can describe as dvi-tellurium, Dt having an atomic weight of 212, and the property of forming the oxide $\mathrm{DtO}_{3}$. If this element really exists ... 
Dvi-tellurium is, of course, polonium. To date, only $\mathrm{PoO}$ and $\mathrm{PoO}_{2}$ have been prepared.

\section{Implications for teaching}

(1) One implication of all this for the teaching of "pure" chemistry is that we need to do justice to the different kinds of understanding that the subject involves. In particular, we need to resist the present tendency, in both schools and universities, to favour the rational over the intuitive. This not only distorts the subject, but makes it less attractive to students who would become good intuitive chemists. Correcting this problem means giving as much attention to those parts of chemistry that cannot easily be understood in rational terms (polymers, intermetallic compounds, colloid and surface chemistry, etc.) as we give to those that can.

This point has been well made by Theobald (1976). In an interesting article on the philosophy of chemistry, he argues that chemistry occupies a special position in science as being an area in which explanations of the kind used in physics "rub shoulders with" explanations of the kind used in biology, and that this is one of the great values of chemistry from an educational point of view. "But," he goes on, "chemists will continue to enjoy this stimulating position only if they resist the temptation to model their science exclusively on either physics or biology." "This," he says, "would be methodologically indefensible, besides being a severe limitation on the chemical imagination." See also Jensen (1986), Scerri and Fisher (2016), and Ball (2017).

(2) A second implication of the nature of "pure" chemistry is that we need to present each topic in a way that is appropriate to the kind of understanding that the topic entails. This means in particular that we need to present the appropriate number of facts on each topic. The point is that an intuitive understanding requires a relatively full exposure to all the facts, whereas a rational understanding requires relatively little-just enough to make the basic principles meaningful.

Take, for example, the chemistry of the elements and the Periodic Table. We saw earlier that the Periodic Law is only approximate and that intuition enters into its application. For students to form an accurate impression of the law, therefore, they require a fairly good knowledge of the chemistry of a fairly large number of elements. Thus, if we try to cut down on the number of facts that beginners need to know before they meet the Periodic Table, what can happen, if we are not very careful, is that they get a very false impression of how good the Periodic Law is, and arrive at wrong conclusions about the chemistry of elements that they have not met. Suppose, for example, we limit their knowledge of elements that appear in the same group to the alkali metals, alkaline earth metals, and halogens. They would then form an unduly favourable impression of the similarity of elements in the same group, and would have a wrong picture of the chemistry of elements in other groups (e.g. they would be led to think that the chemistry of lead is as similar to that of carbon as the chemistry of caesium is to that of lithium). Partington wrote that the Periodic Table is "all but meaningless to a beginner" (1929, p. 235). 
This problem is not resolved by introducing the Periodic Table via electronic configuration. The latter is a third-level concept, and requires a long introduction to be intelligible. Indeed, it is most easily introduced via the Periodic Table itself (Nelson 2002, 2017).

(3) The approximate character of many chemical theories means that we need to present them critically. We need to show, not only how well they work, but what their limitations are. An obvious example is the Periodic Table which we have discussed already, but other examples are:

(i) When we predict the shape of a molecule by reckoning up the number of electron pairs around the central atom, we should point out that this does not always give the right result (e.g. it fails for the $\mathrm{SeCl}_{6}{ }^{2-}$ and the $\mathrm{TeCl}_{6}{ }^{2-}$ ion, which have a regular octahedral structure).

(ii) When we use differences in electronegativity to gauge the ionic character of bonds, we should remember that this does not always work (e.g. caesium is more electropositive than lithium, but, while $\mathrm{Li}_{2} \mathrm{O}$ is white and has the antifluorite structure, $\mathrm{Cs}_{2} \mathrm{O}$ is orange-yellow and has a layer structure).

(iii) When using the "inductive" and the "mesomeric" effect to predict the course of an organic reaction, we should make it clear that this approach sometimes gives the wrong answer (e.g. in the case of the direction of substitution in chlorobenzene). Organic chemists are not always sure which way the arrows should go when they use this approach.

(4) A further consequence of the character of chemical theories is that, for the presentation of certain topics, the best approach is a historical or semi-historical one. I have in mind particularly those concepts which have evolved in meaning over the years, and whose present meaning depends, to some extent at least, on an earlier meaning. Take, for example, the concept of "acidity" and "basicity". Modern definitions of "acid" and "base" ("proton donor" and "proton acceptor", "producer of cation characteristic of the solvent" and "producer of anion characteristic of the solvent", "oxide ion donor" and "oxide ion acceptor", "electron pair acceptor" and "electron-pair donor") are not independent of the original idea of an "acid" (a sour-tasting substance which turns blue litmus red) and base (a substance that neutralizes an acid and turns red litmus blue). They are attempts to specify what it is that makes "acids" and "bases", in the original sense of the words, the species they are, and to produce a more general classification on the basis of it. Without this connection, the use of the word "acid" and "base" becomes very confusing: why use the same words in so many different ways, and why call, for example, $\mathrm{CH}_{3} \mathrm{CO}_{2} \mathrm{H}$ acetic "acid" when it is quite often said to act as a base (e.g. in $\mathrm{H}_{2} \mathrm{SO}_{4}$ and liquid $\mathrm{HF}$ ). A historical treatment of "acidity" and basicity" is therefore essential (cf. Jensen 1980).

Other examples of concepts that have evolved in meaning over the course of time are "oxidation" and "reduction", "electronegativity", "simple" and "complex" compounds, and the Periodic Table itself. These concepts too are best presented semi-historically (cf. Phillips and Williams 1965, p. 291, "The causes of the attitudes of mind which have been adopted by chemists are best treated on a semi-historical basis").

A historical component in the teaching of "pure" chemistry has the merit of drawing attention to the people who have contributed to the subject, and of representing 
chemistry for what it is: a human activity. Also, it sets the subject in a temporal perspective, and helps to convey the idea that "pure" chemistry, far from having arrived at its final form, is still in a state of development.

\section{"Applied" chemistry: its scope}

My fourth proposition is that "applied" chemistry is a very-wide ranging activity. Thus:

(1) it comprises not only the chemical industry (i.e. the manufacture of materials), but a whole range of other activities - the purification of tap water, the treatment of wastes, the analysis of medical samples, forensic chemistry, etc.;

(2) the materials that are produced by the chemical industry, and the equipment that is used to produce them, vary very widely - from pig iron made in blast furnaces and petrol in refineries to pharmaceuticals made in glassware and precious metal salts at the bench;

(3) the chemical industry supplies materials to almost every other industry, and, directly or indirectly, impinges on almost every area of our lives (i.e. on our food, clothing, homes, health, transport, communication, recreation, etc.);

(4) the chemical industry is one of the largest industries, and, because of its dependence on raw materials, and its provision of materials that are essential to other industries, it plays a major part in world trade, and a significant part in world politics (e.g. in relation to Middle East oil, or to the rich deposits of important metals in Southern Africa).

So great is the scope of "applied" chemistry that to get an accurate picture of it, and to convey this picture to students, is difficult. The current tendency is to present "applied" chemistry largely in terms of the chemical industry, and the chemical industry largely in terms of processes that are new and well understood. This fails to do justice to whole areas of "applied" chemistry, from the use of chemistry in the public service sector of society to the manufacture of pottery, paper, and glass. Teachers have to try to avoid such distortions, and to present the subject as faithfully as they can.

As with "pure" chemistry, there is a place for the introduction of a certain amount of history in the teaching of "applied" chemistry. This facilitates the presentation of practices that have become increasingly complicated over the years (e.g. the extraction of metals), and helps in trying to convey the tremendous influence "applied" chemistry has on our lives (e.g. as a result of the synthesis of antibiotics). As Sherwood Taylor wrote, "The past gave birth to the present, and we can understand ourselves and our age only in the light of the past whose ideas we inherit and whose air we still breathe" (1957, p. 8). At the very least, a historical perspective helps us to avoid the mistake of becoming so taken up with the very latest discoveries (as, e.g., one school text is with carbon fibres) that we fail to mention older practices that continue to give excellent service (e.g. the many uses of graphite).

In the teaching of "applied" chemistry, there is also a place for taking students actually to see "applied" chemistry in action. They do not necessarily need to understand what is going on (e.g. in a steelworks) to benefit from the experience. There is a great need to bring "applied" chemistry into the sphere of students' experience. Only then does it become "real" to them, and attain its proper significance. 


\section{Cerebral and practical}

My fifth proposition is that chemistry is both an intellectual activity and a practical one, and that the latter is as important as the former. Most chemical operations require considerable practical skill, and no amount of intellectual understanding can act as a substitute for this, invaluable though it may be. Moreover, the practical skills that are required for different operations vary very widely. There is a great deal of difference between the techniques involved in, for example, synthesizing a new compound, carrying out a physico-chemical measurement, and manufacturing a material on a large scale.

The implications of this for the teaching of chemistry are that (1) the practical side of the subject needs to be given as much attention as the theoretical side, and (2) the training that is given is broad. It is not enough simply to get students to carry out key experiments in order to "discover" or verify chemical principles, though this does, of course, have its place. They also need to be trained in various manipulative techniques, in the same way as a metalworker is trained to file, solder, weld, etc. Chemical techniques require practice, and there is no substitute for this. In addition, at university level at least, students need to be given "real life" exercises to do, so that they can get some idea of how to apply their skills to practical problems.

The need for chemists to receive a good practical training cannot be emphasized enough. In many of the things chemists do, mistakes can have serious consequences-whether in the analysis of a specimen in a hospital, the running of a hazardous process on a plant, or the disposal of radioactive wastes. When we have an operation, we like to think that the surgeon is skilled in what he has to do. In the same way, we need chemists who are skilled in what they do-who have practical ability as well as theoretical.

\section{Analytical chemistry}

A branch of chemistry that needs to receive more attention than it often does is analytical chemistry. The importance of this branch can scarcely be overstated. It is essential to chemical research, and to the day-to-day running of the chemical industry; it is essential also in other areas of science, and it makes important contributions to many of the social services (health, criminal investigations, consumer protection, etc.). Furthermore, while analytical chemistry has much in common with the rest of chemistry, it is, in many respects, very distinctive. It approaches problems in its own way, uses its own techniques, and has its own skills. It is not something that can be picked up very easily without specific instruction and training.

\section{Part of a whole}

My final proposition is that chemistry is not an isolated activity, but is inextricably connected with other human activities. It is not a subject that can be presented completely independently of other subjects, but one that can only be properly appreciated in relation to the whole of which it is a part.

"Pure" chemistry, of course, forms part of the general quest for an understanding of the universe. In its development, it has been greatly influenced by progress in physics; and 
in recent times it has contributed greatly to the development of biology and geology. To appreciate "pure" chemistry fully, therefore, it has to be set in its context in science as a whole.

Likewise, "applied" chemistry forms part of the general practical activity of humankind, and is closely related to other technical pursuits, like building, farming, engineering, and medicine, from which it cannot be separated completely. Furthermore, the practice of "applied" chemistry is greatly influenced by economic, social, political, and ultimately ideological or religious considerations. The last enter, for example, in the choice between a chemical business that concentrates on making money for directors and shareholders and one that builds houses for its workers and looks after their welfare (as some Christian businesses did during the Industrial Revolution).

Ideological considerations also enter into the pursuit of "pure" chemistry. As we have seen, the extent to which "pure" chemists think of the needs of "applied" chemists when they do their work depends on their personal ideology. In addition, when a hypothesis is under debate, the side that they take in the argument can be greatly affected by their personal beliefs. A good example from the history of chemistry is provided by the atomic theory, which, following its enunciation by Dalton in 1803, was strongly contested throughout the 19th century by positivists, who, being unwilling to believe in anything that they could not in some way observe, found the evidence that was then available for the existence of atoms too indirect to be acceptable. Opposition to the atomic theory continued into the 20th century, and only subsided after one of the leading dissenters, the physical chemist Ostwald, withdrew his objection to it in 1907, after Einstein had shown that Brownian motion could be accounted for in terms of molecular bombardment of the particles in motion (Knight 1967).

A contemporary example in chemistry is Oparin's hypothesis that life originated on earth by a process of "chemical evolution" in the primitive oceans, an idea that is readily accepted by those who believe that the uniformity of nature is total, but is contested by those who believe that the Bible teaches otherwise. Another contemporary example in science is the interpretation of the quantum theory and the nature of the electron. The question is, is the electron a mysterious entity which sometimes behaves like a particle and sometimes like a wave, or is it simply a particle which derives its wave-behaviour from a sub-electronic medium, in the same kind of way that a buoy does from the sea, or a pollen grain executing Brownian motion gets its movement from the water? The controversy here is similar to that over the atomic theory, with positivists opting for the former, and a growing number of critics contending for the latter (see, e.g., Davies and Brown 1986).

The implication of all this for the teaching of chemistry is that, to do full justice to the subject, we need to set it in its wider context. We need to give some indication of its relationship to other subjects and activities, and of the various considerations that enter into its practice.

\section{Conclusion}

As I have defined it, chemistry is a much broader subject than the one that is currently being taught in schools and universities, majoring as it does on "pure" chemistry and "rational" theory. I submit that those of us who are responsible for the teaching of chemistry should try to enlarge our conception of the subject, and to deal with those aspects of it that we are presently tending to neglect. 
Acknowledgements I am grateful to colleagues and friends with whom I have discussed the teaching of chemistry at various times, and to a reviewer for constructive comments.

Open Access This article is distributed under the terms of the Creative Commons Attribution 4.0 International License (http://creativecommons.org/licenses/by/4.0/), which permits unrestricted use, distribution, and reproduction in any medium, provided you give appropriate credit to the original author(s) and the source, provide a link to the Creative Commons license, and indicate if changes were made.

\section{References}

Ball, P.: The philosopher's quest. Distillations, Fall (2017)

Berman, R., Simon, S.F.: On the graphite-diamond equilibrium. Z. Elektrochem. 59, 333 (1955)

Bundy, F.P., Hall, H.T., Strong, H.M., Wentorf Jr., R.H.: Man-made diamonds. Nature 176, 51 (1955)

Davenport, D.A.: The grim silence of facts. J. Chem. Educ. 47, 271 (1970)

Davies, P.C.W., Brown, J.R. (eds.): The Ghost in the Atom. Cambridge University Press, Cambridge (1986)

Hart, H.L.A.: The Concept of Law. Oxford University Press, Oxford (1961)

Hughes, W.: In: Daniels, D.J. (ed.) New Movements in the Study and Teaching of Chemistry. Temple Smith, London (1975)

Jensen, W.B.: The Lewis Acid-Base Concepts. Wiley, New York (1980)

Jensen, W.B.: Classification, symmetry, and the Periodic Table. Comput. Math Appl. 12B, 487 (1986)

Johnson, D.A., Nelson, P.G.: Valencies of the lanthanides. Found. Chem. 20, 15 (2018)

Knight, D.M.: Atoms and Elements. Hutchinson, London (1967)

Langrish, J., Gibbons, M., Evans, W.G., Jevons, F.R.: Wealth from Knowledge. Macmillan, London (1972)

Lewis, G.N.: The Anatomy of Science. Yale University Press, New Haven (1926)

Mendeleev, D.: The Principles of Chemistry, vol. II. Longmans, Green, and Co., London (1891)

Mendeleev, D.: Faraday Lectures 1869-1928. The Chemical Society, London (1889/1928)

Nelson, P.G.: Teaching chemistry progressively: from substances, to atoms and molecules, to electrons and nuclei. Chem. Educ. Res. Pract. 3, 215 (2002)

Nelson, P.G.: Periodicity in the formulae of carbonyls and the electronic basis of the Periodic Table. Found. Chem. 15, 199 (2013)

Nelson, P.G.: Introduction to Chemistry: A progressive approach. http://bookboon.com/en/introduction-tochemistry-ebook (2017)

Partington, J.R.: Everyday Chemistry. Macmillan, London (1929)

Partington, J.R.: General and Inorganic Chemistry. Macmillan, London (1946)

Partington, J.R.: A Short History of Chemistry, 3rd edn. Macmillan, London (1957)

Phillips, C.S.G., Williams, R.J.P.: Inorganic Chemistry, vol. I. Oxford University Press, Oxford (1965)

Scerri, E., Fisher, G. (eds.): Essays in the Philosophy of Chemistry. Oxford University Press, Oxford (2016)

Sherwood Taylor, F.: A History of Industrial Chemistry. Heinemann, London (1957)

Theobald, D.W.: Some considerations on the philosophy of chemistry. Chem. Soc. Rev. 5, 203 (1976)

Wang, G., et al.: Identification of an iridium-containing compound with a formal oxidation state of IX. Nature 514, 475 (2014) 